\title{
THE AFGHAN WAR AGAINST DENTAL DISEASE
}

A charity is looking for volunteers from the dental profession to provide services to Afghanistan, a country with almost 30 million people that have no basic dental care.

Since first visiting Afghanistan in 2003 with all the equipment he could carry strapped to his back, Dr James Rolfe has made the Kabul Dental Clinic and Training Center a reality and established the Afghanistan Dental Relief Project (ADRP).

Dr Rolfe, of Santa Barbara, California, created his dental clinic in some 40 foot shipping containers constructed of safe, solid steel with their own water supply, plumbing, storage, electrical systems, artwork, music and supplies. They also contain dental chairs, X-ray machines and a laboratory area.
The Afghan Dental Relief Project is an organisation established to provide dental treatment facilities in underserved areas of Afghanistan, to staff these facilities with volunteers, to train the Afghan people in dentistry and modern technology at no cost to the needy and to provide instruction in preventive dental care.

The volunteer centre opened in Kabul in January 2009, next door to the clinic, and has seven bedrooms and complete utilities designed to host many volunteers in complete comfort and security.

As well as calling for volunteers, the ADRP are hoping to raise funds for the shipping of a third container to expand the much-needed clinic.

For more information on volunteering or donating, visit www.adrpinc.org.

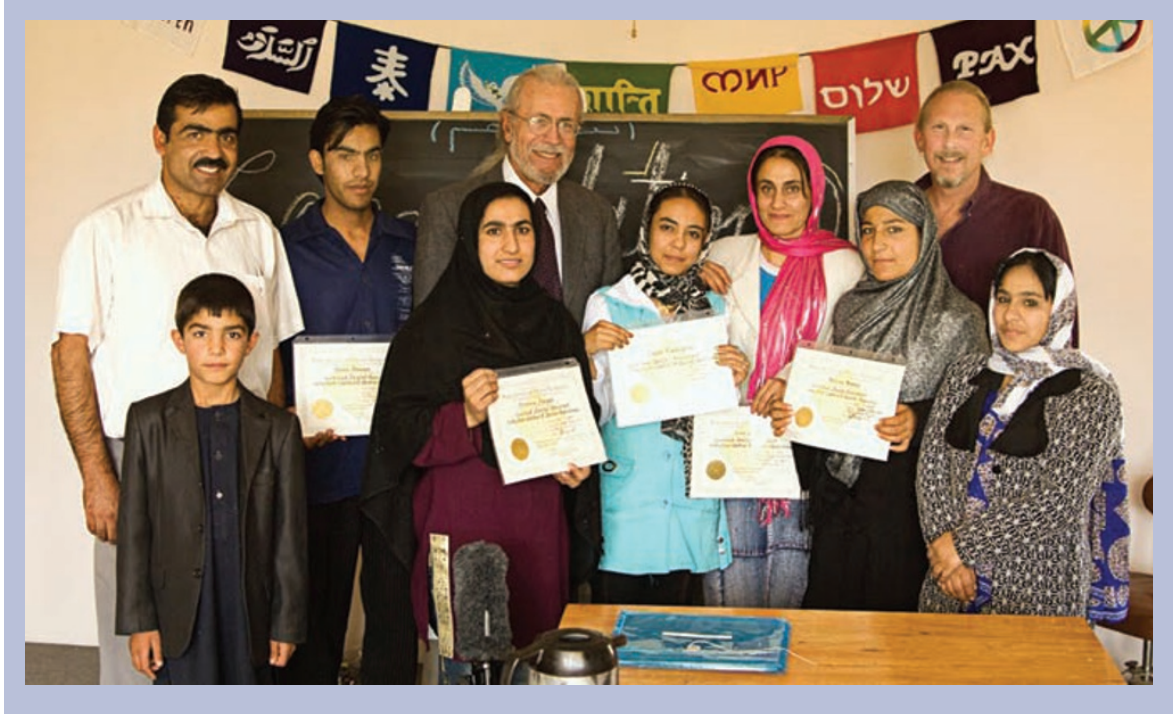

\section{LOOK OUT FOR UNEXPECTED PENSION TAX}

The Government's recently announced change in the Annual Allowance for pensions from 6 April 2011 will drastically reduce the amount that individuals can pay into a pension scheme and benefit from tax relief from $£ 225,000$ to just $£ 50,000$ a year.

This may come as a surprise to dentists who think their contributions in the current tax year of over $£ 50,000$ are safe. This is because pension contributions for the Annual Allowance are subject to what is called a Pension Input Period (PIP) and the PIP for many investors may end during the 2011/12 tax year. In this case, even pension contributions made in the current financial period could be liable for tax. 'The lowering of the Annual Allowance to $£ 50,000$ will affect a lot of dentists, particularly those who are members of final salary schemes,' said Clive Weir, Director at Albert Goodman Chartered Financial Planners. 'However, this can be easily avoided by identifying when your PIP ends and then electing to change it.'

Albert Goodman advise any concerned dentists to seek the services of a financial planner or accountant to ensure that tax liabilities are minimised. 